\title{
PERANCANGAN JARINGAN DAN OTOMASI STUDIO TERINTEGRASI STASIUN RADIO STREAMING
}

\author{
Budi Santoso ${ }^{1)}$, Edi Prihartono ${ }^{2)}$ \\ ${ }^{1,2}$ Faculty of Engineering Dr.Soetomo University \\ email: santosobudi.id@gmail.com ${ }^{1)}$, \\ edi.prihartono72@gmail.com ${ }^{2}$
}

\begin{abstract}
The recent communication media technology has reached the era of convergence where it required to provide information and content in various forms,such as in text, sound, or image.The similar situation also happens at radio broadcasting. With the revolution of computer and internet network technology, currently radio broadcast has possibility to cross the range of conventional broadcast radius over internet network or called radio streaming. Dr. Soetomo University as one of the universities which have a competence in the field of communication science and information technology, must also be able to adapt to the latest developments in radio broadcasting technology and its methods.

The general objective of this research is to create integrated network modeling and studio automation for streaming radio stations at Dr.Soetomo University that is able to adapt environmental conditions ie: data traffic on network, broadcast schedule, weather conditions, etc.

The research method used is Research and Development ( $R \& D)$ using design studio model integrated phase and audio network automation design phase which is used for broadcasting process of radio broadcast via internet.
\end{abstract}

Keywords: streaming radio, integrated studio, media convergence

\section{PENDAhULUAN}

Pesatnya perkembangan teknologi informasi dan komunikasi atau yang dikenal dengan istilah Information and Communication Technology (ICT) dan internet telah merambah berbagai bidang kehidupan tidak terkecuali bidang hiburan dan penyiaran. Di sisi lain dengan adanya ICT proses produksi dan penyiaran dapat dilakukan kapan saja tanpa terikat ruang dan waktu. Dewasa ini terjadi pergeseran dalam proses penyiaran dengan berkembangnya penggunaan teknologi informasi yaitu, dari proses manual menjadi ter-otomasi, dari konten yang terbatas menjadi bervariasi, serta dari interaksi fisik menjadi interaksi maya (virtual).

Pada dunia pendidikan, penyebaran informasi yang bermanfaat juga dibutuhkan oleh masyarakat akademis maupun umum. Stasiun radio kampus merupakan salah satu media yang efektif dalam meningkatkan penyampaian arus informasi dan komunikasi di masyarakat, khususnya masyarakat di sekitar kampus. Perguruan tinggi sebagai agen perubahan perlu mendapatkan wadah kegitan yang bersifat independent dan terarah.sebagai media yang dapat menyalurkan hobby dan minat serta sebagai pengamalan dari Tridharma Perguruan tinggi. Melalui sebuah stasiun radio streaming yang mengintegrasikan sebagian ruang kampus inilah diharapkan dosen, mahasiswa, serta seluruh sivitas akaemik dapat berperan serta menyampaikan informasi yang positif dan membangun bagi masyarakat. 


\subsection{KAJIAN LITERATUR}

\section{Radio Broadcasting}

Radio adalah teknologi yang digunakan untuk pengiriman sinyal dengan cara modulasi dan radiasi elektromagnetik(gelombang elektromagnetik). Gelombang ini melintas dan merambat lewat udara dan bisa juga merambat lewat ruang angkasa yang hampa udara, karena gelombang ini tidak memerlukan medium pengangkut (seperti molekul udara).

Gelombang radio adalah satu bentuk dari radiasi elektromagnetik, dan terbentuk ketika objek bermuatan listrik dimodulasi (dinaikkan frekuensinya) pada frekuensi yang terdapat dalam frekuensi gelombang radio (RF) pada suatu spektrum elektromagnetik, dan radiasi elektromagnetiknya bergerak dengan cara osilasi elektrik maupun magnetik.

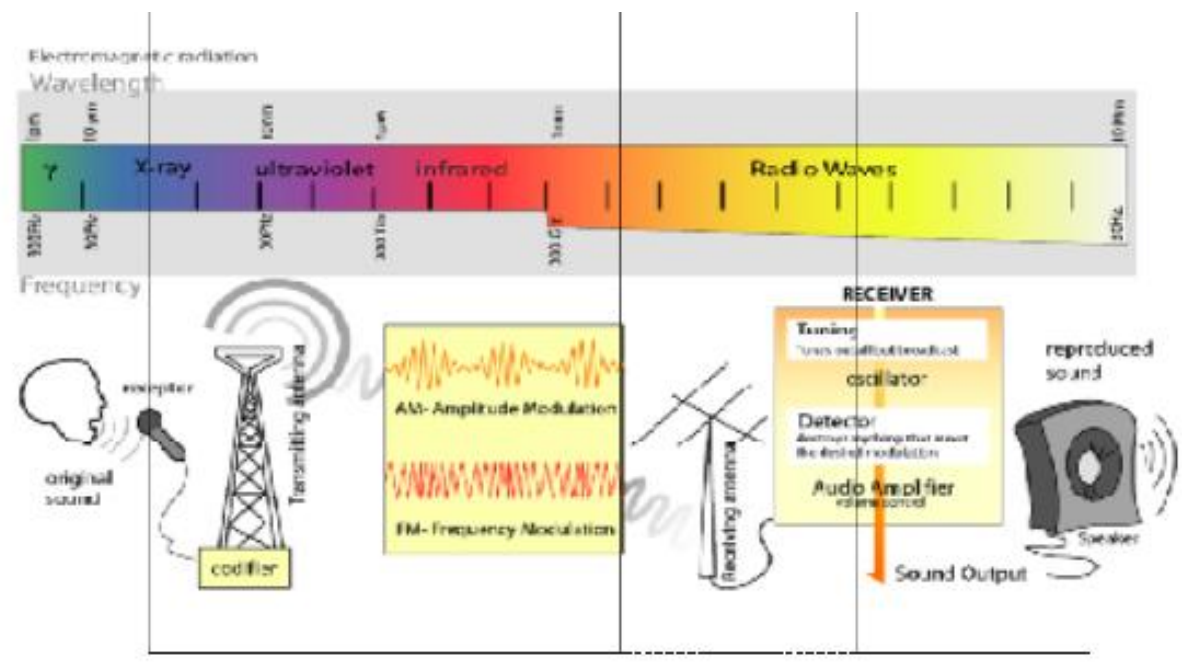

Gambar 1. Spektrum frekuensi radio

Gelombang elektromagnetik lain yang memiliki frekuensi di atas gelombang radio meliputi sinar gamma, sinar-X, inframerah, ultraviolet, dan cahaya terlihat. Ketika gelombang radio dipancarkan melalui kabel, osilasi dari medan listrik dan magnetik tersebut dinyatakan dalam bentuk arus bolak-balik dan voltase di dalam kabel. Hal ini kemudian dapat diubah menjadi signal audio atau lainnya yang membawa informasi.

\section{Jenis Teknologi Penyiaran Radio}

Berdasarkan cara melakukan transmisi siaran, radio dapat dikategorikan menjadi 2 kelompok yaitu Radio Analog dan Radio Digital. Terdapat dua metode transmisi gelombang audio pada kategori radio analog, yaitu melalui modulasi amplitudo (AM) dan modulasi frekuensi (FM). 


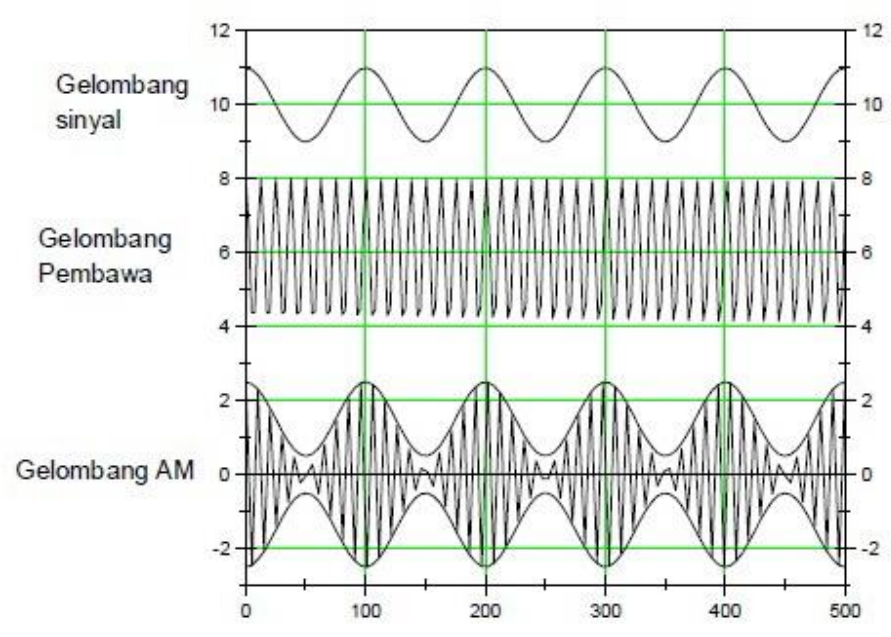

Gambar 2. Gelombang Radio AM

Radio AM (modulasi amplitudo) bekerja dengan prinsip memodulasikan gelombang radio dan gelombang audio. Kedua gelombang ini sama-sama memiliki amplitudo yang konstan. Namun proses modulasi ini kemudian mengubah amplitudo gelombang penghantar (radio) sesuai dengan amplitudo gelombang audio.

Radio FM (modulasi frekuensi) bekerja dengan prinsip yang serupa dengan radio AM, yaitu dengan memodulasi gelombang radio (penghantar) dengan gelombang audio. Hanya saja, pada radio FM proses modulasi ini menyebabkan perubahan pada frekuensi.

Ketika radio AM umum digunakan, Armstrong menemukan bahwa masalah lain radio terletak pada jenis sinyal yang ditransmisikan. Pada saat itu gelombang audio ditransmisikan bersama gelombang radio dengan menggunakan modulasi amplitudo (AM). Modulasi ini sangat rentan gangguan cuaca. Pada akhir 1920-an Armstrong mulai mencoba menggunakan modulasi dimana amplitudo gelombang penghantar (radio) dibuat konstan. Pada tahun 1933 akhirnya ditemukan sistem modulasi frekuensi (FM) yang menghasilkan suara jauh lebih jernih, serta tidak terganggu oleh cuaca buruk.

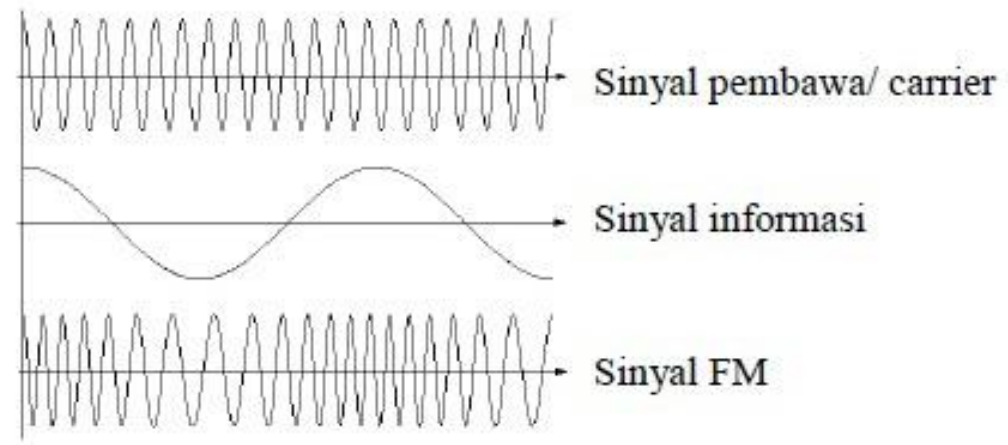

Gambar 3. Gelombang Radio FM

Pada radio digital atau biasa disebut radio satelit, siaran ditransmisikan gelombang audio menggunakan sinyal digital. Berbeda dengan sinyal analog yang menggunakan gelombang kontinyu, gelombang suara ditransmisikan melalui sinyal digital yang terdiri atas kode-kode biner 0 dan 1 . Sinyal ini ditransmisikan ke daerah jangkauan yang jauh lebih luas namun hanya dapat diterima oleh perangkat khusus yang bisa menerjemahkan sinyal terenkripsi. 


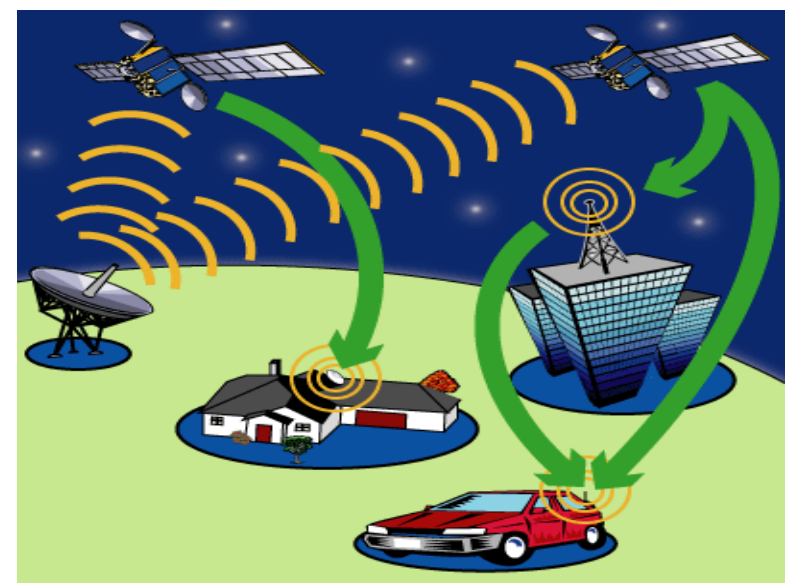

Gambar 4. Ilustrasi Radio Digital / Satelit

Siaran radio satelit juga hanya bisa diterima di tempat terbuka dimana antena pada pesawat radio memiliki garis pandang dengan satelit pemancar. Radio satelit hanya bisa bekerja yang tidak memiliki penghalang besar seperti terowongan atau gedung. Untuk mendapat transmisi siaran yang baik, perlu dibuat stasiun repeater agar kualitas layanan prima.

\section{Radio Streaming}

Penemuan internet mulai merubah transmisi sinyal analog yang digunakan oleh radio konvensional. Radio internet (dikenal juga sebagai web radio, radio streaming dan eradio) bekerja dengan cara mentransmisikan gelombang suara lewat internet. Prinsip kerjanya hampir sama dengan radio konvensional yang gelombang pendek (short wave), yaitu dengan menggunakan medium streaming berupa gelombang yang kontinyu.

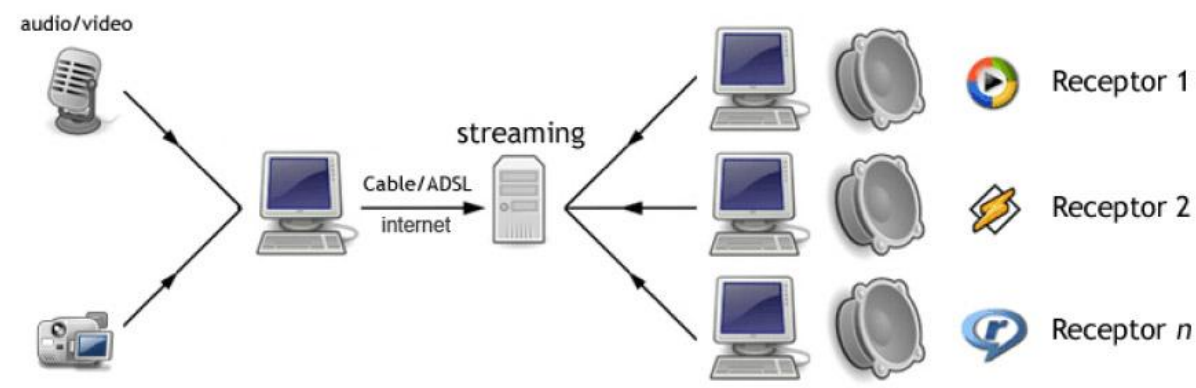

Gambar 5. Skema Radio Streaming

Sistem kerja ini memungkinkan siaran radio terdengar ke seluruh dunia asalkan pendengar memiliki perangkat internet. Di Indonesia, umumnya radio internet dikolaborasikan dengan sistem radio analog oleh stasiun radio teresterial untuk memperluas jangkauan siarannya.

\section{Jaringan Studio Terintegrasi}

Umumnya sebuah stasiun radio hanya membutuhkan sebuah ruangan untuk melakukan aktifitas siaran. Namun, pada sebuah stasiun radio pendidikan dimana ada banyak event yang memungkinkan untuk disiarkan, siaran harus dapat dilakukan di ruangan manapun asalkan dapat terhubung dengan studio utama. 
Menghubungkan beberapa ruangan dalam sebuah skema siaran melalui jaringan audio akan membutuhkan sumber daya yang cukup besar dan kompleks. Namun dengan perkembangan teknologi informasi, dimana sebuah informasi audio dapat dikonversi menjadi sekumpulan data

\section{METODE PENELITIAN}

Penelitian dilakukan dalam 2 tahapan yaitu perancangan model jaringan studio terintegrasi dan perancangan otomasi siaran yang melibatkan studio terintegrasi.

Pada perancangan model jaringan studio terintegrasi, radio streaming Unitomo direncanakan melibatkan minimal 2 studio, dimana sebuah studio berfungsi sebagai pusat pengendali siaran dan studio lain sebagai pendukung pada saat diperlukan event siaran khusus.

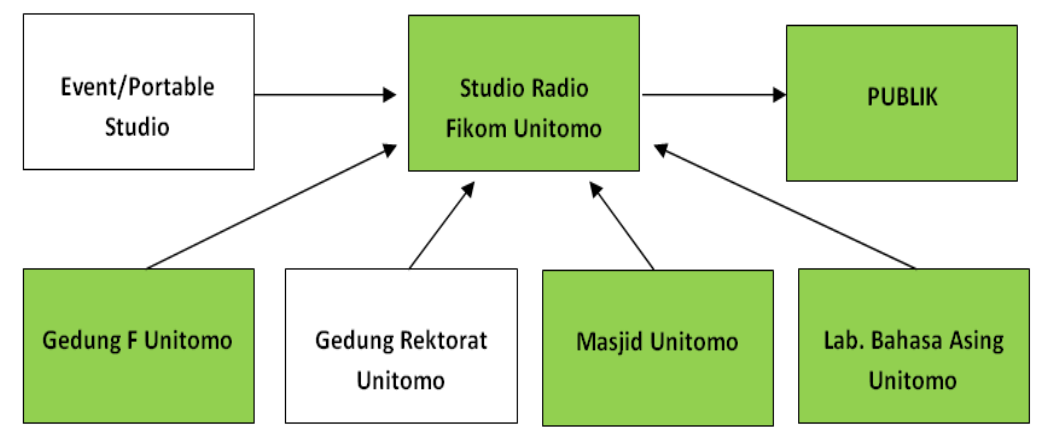

Gambar 6. Bagan fisik model studio terintegrasi

Hubungan antar ruang studio memanfaatkan koneksi jaringan kabel (LAN) dan Wifi yang telah tersedia di lingkungan kampus Universitas Dr.Soetomo Surabaya.

Secara garis besar, dasar topologi jaringan yang akan dibangun adalah sebagai berikut :

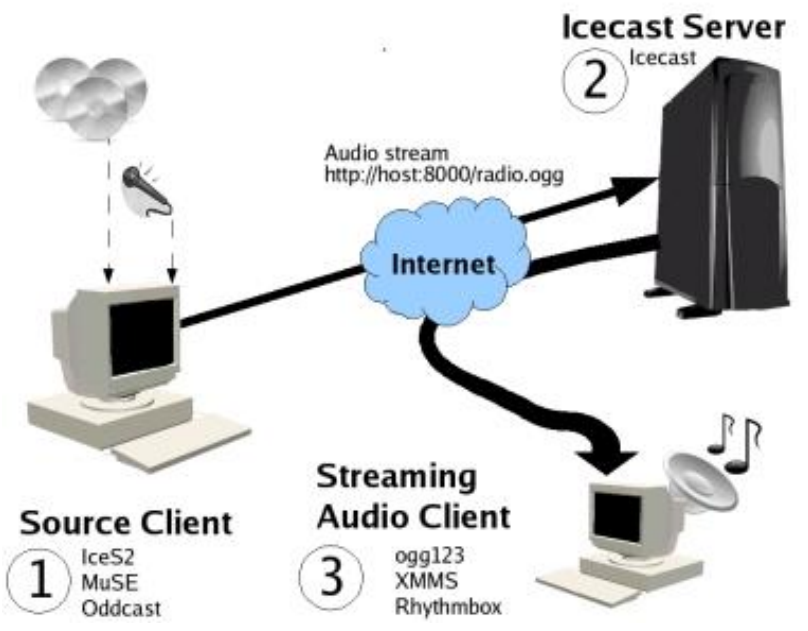

Gambar 7. Topologi jaringan radio streaming

Sedangkan pada otomasi jaringan studio terintegrasi digunakan untuk mengatur lalu lintas data audio yang berasal dari tiap ruang studio, agar dapat digunakan secara simultan setiap saat tanpa harus melakukan persiapan instalasi jaringan.

Agar dapat dilakukan proses otomasi lalu lintas data audio, ditambahkan sebuah aplikasi jaringan pada server. Aplikasi harus mampu menangani perpindahan saluran baik manual ataupun otomatis pada saat terjadi perpindahan ruang studio siaran. Selain itu aplikasi juga harus 
mampu menghubungkan 2 ruang studio yang berbeda untuk bersama-sama melakukan siaran secara live.

\section{HASIL DAN PEMBAHASAN}

\section{Unit Studio Terintegrasi}

Implementasi jaringan studio terintegrasi memanfaatkan perangkat keras mini PC Raspberry Pi yang telah didukung dengan sistem operasi Linux Raspibian dan fitur wifi untuk koneksi ke jaringan internet. Agar dapat dimanfaatkan sebagai sebuah stasiun radio streaming terintegrasi, terlebih dulu pada Raspberry Pi harus dilakukan instalasi software Icecast2 Server dan DarkIce.

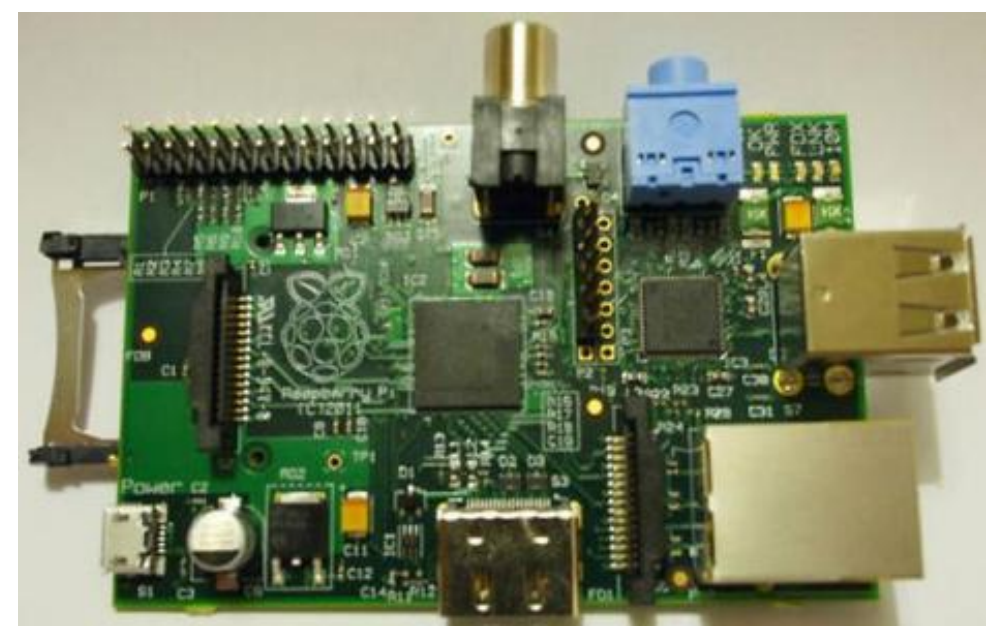

Gambar 8. Mini PC Raspberry Pi

Instalasi SoftIce2 dan DarkIce dilakukan dengan mengambil aplikasi dari repository Raspbian : sudo apt-get install softice2

sudo apt-get install darkice

Sebelum dapat digunakan terlebih dulu harus dilakukan pembuatan file konfigurasi server streaming dengan isi sebagai berikut :

$<$ Hostname $>--D N S$ name or IP address used for stream directory listings.

$<$ Source password $>$--will be used for the source client authentication

$<$ adminpassword $>$--will be used for authenticating admin features of icecast

$<$ listen socket $>--($ both port and bind address)

$<$ logdir>--directory where log files will be placed

$<$ webroot $>-$-directory for non admin content (file serving

root), status page is provided

$<$ adminroot $>--$ directory containing admin xslt files

$<$ mount $>$

$<$ mountname $>$ /examplecomplex.ogg

$</$ mountname $>$

$<$ username $>$ source $<$ /username $>$

$<$ password $>$ hackme $<$ password $>$

$</$ mount $>$

Selanjutnya dilakukan perintah starting icecast server stream:

\# icecast -c icecast.xml or from the path as 
\#/opt/icecast/latest/bin/icecast $<$ full path-name $>-c$

/opt/icecast/latest/etc/icecast.xml $<$ config file location path $>-b$

Proses selanjutnya adalah pengecekan kompabilitas audio pada Raspberry Pi untuk dukungan pada software DarkIce serta modifikasi file konfigurasinya

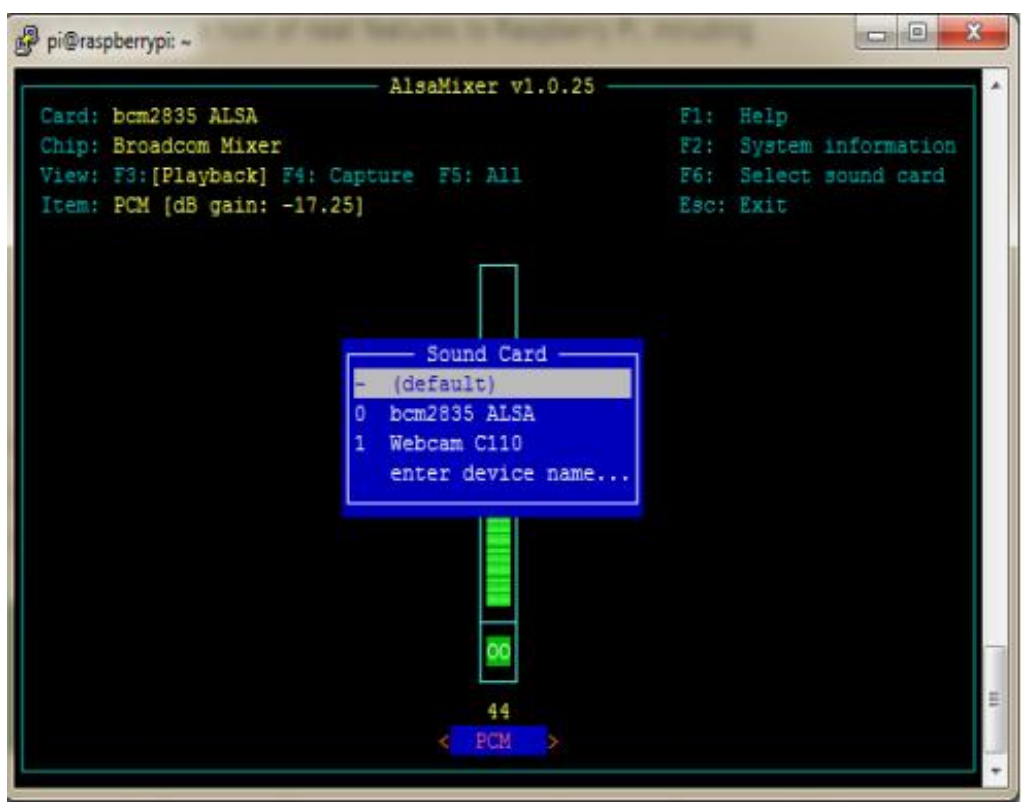

Gambar 9. Dukungan Audio untuk DarkIce

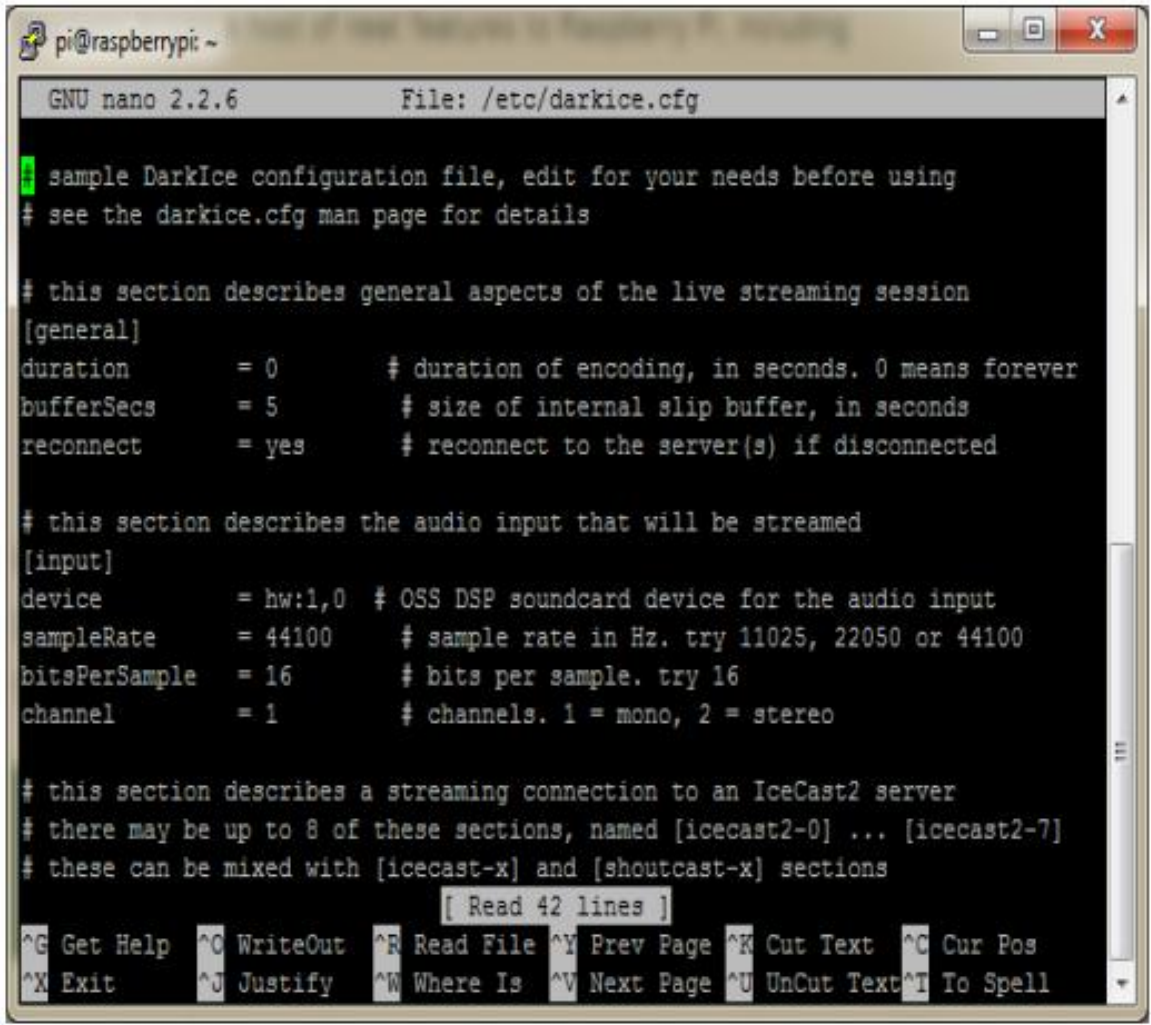

Gambar 10. Modifikasi DarkIce config dengan nano 
Dengan adanya perubahan file konfigurasi Icecast2 dan DarkIce, maka server streaming pada unit studio terintegrasi telah dapat dipergunakan. Untuk hasil pengujian instalasi server dapat dilakukan dengan mengamati monitoring server pada halaman web localhost:nomorport melalui browser:

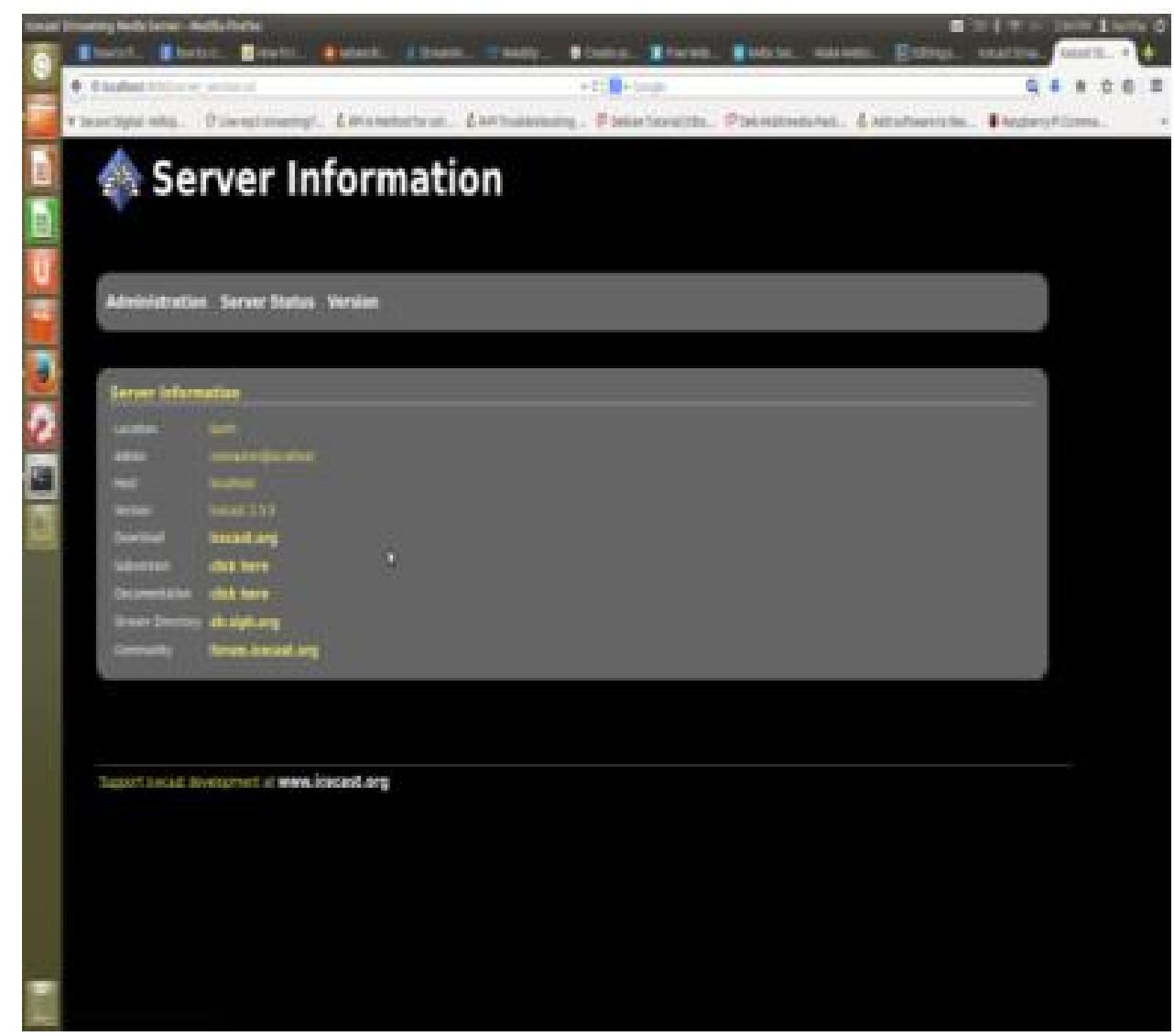

Gambar 11. Monitoring hasil instalasi streaming server pada browser

\section{Otomasi Siaran}

Bagian studio utama pada jaringan studio terintegrasi harus mampu melakukan perpindahan baik secara manual maupun otomatis pada sumber audio siaran. Ada beberapa aplikasi yang sesuai digunakan untuk keperluan ini, diantaranya adalah:

- Aplikasi WinAmp dari Shoutcast

- Aplikasi ZaraRadio

Pengujian otomasi siaran menggunakan aplilkasi WinAmp dilakukan dengan mengisi playlist dengan url server streaming icecast 2 


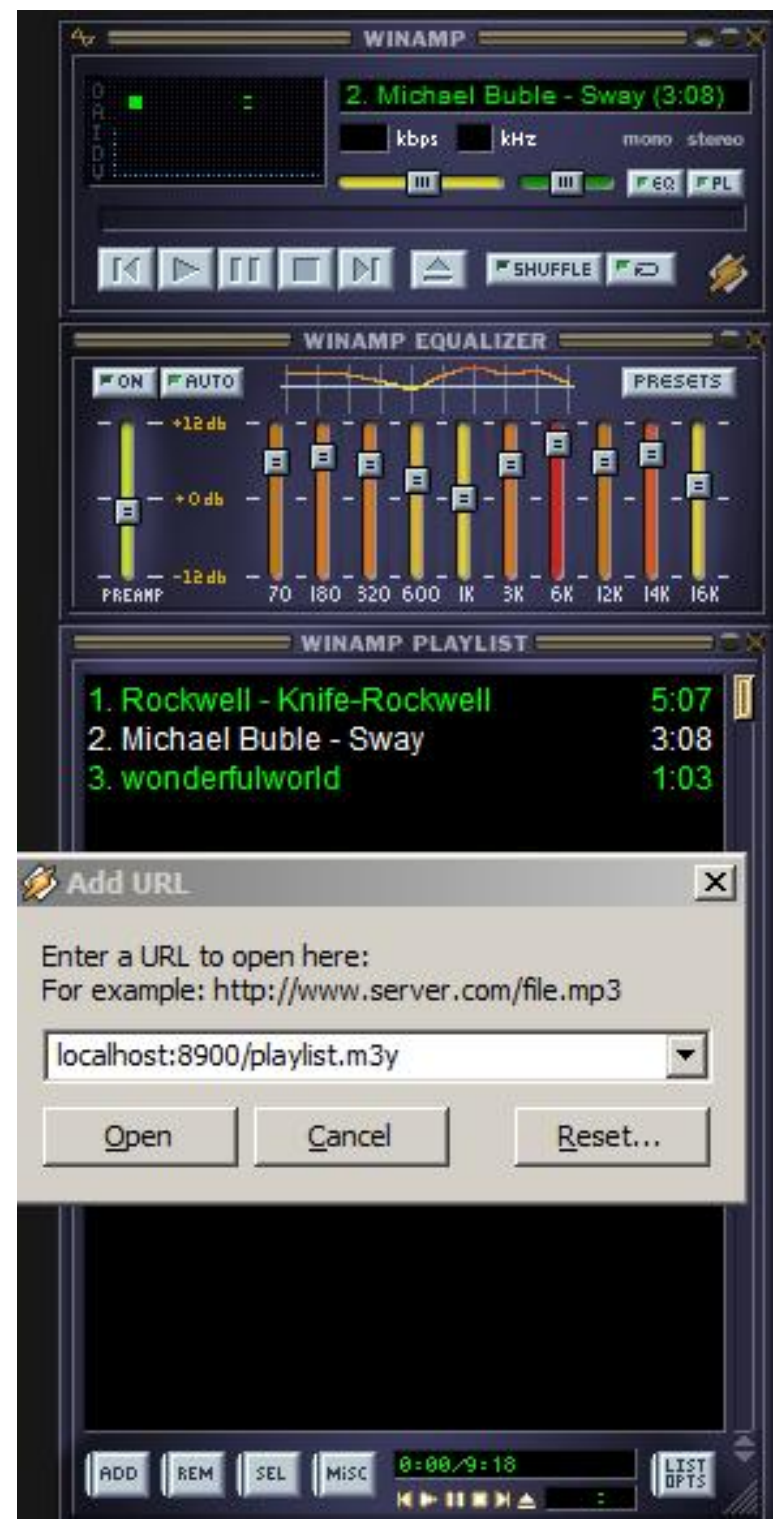

Gambar 12. Otomasi siaran menggunakan WinAmp

Berbeda dengan WinAmp, aplikasi ZaraRadio sebagai bagian otomasi siaran radio mempunyai fitur yang lebih lengkap yaitu sebagai player, log siaran, timer, dan beberapa fitur menarik lainnya. Hal ini disebabkan ZaraRadio memang dibuat khusus sebagai perangkat standar siaran radio broadcast.

Namun ada sebuah kelemahan pada aplikasi ZaraRadio bila ingin digunakan pada sistem siaran studio terintegrasi yaitu pemanfaatan source audio dari sumber streaming yang cukup rumit. Padahal justru fitur inilah yang sangat diperlukan pada sistem siaran studio terintegrasi untuk mengambil suara dari unit studio lain di luar studio utama. 


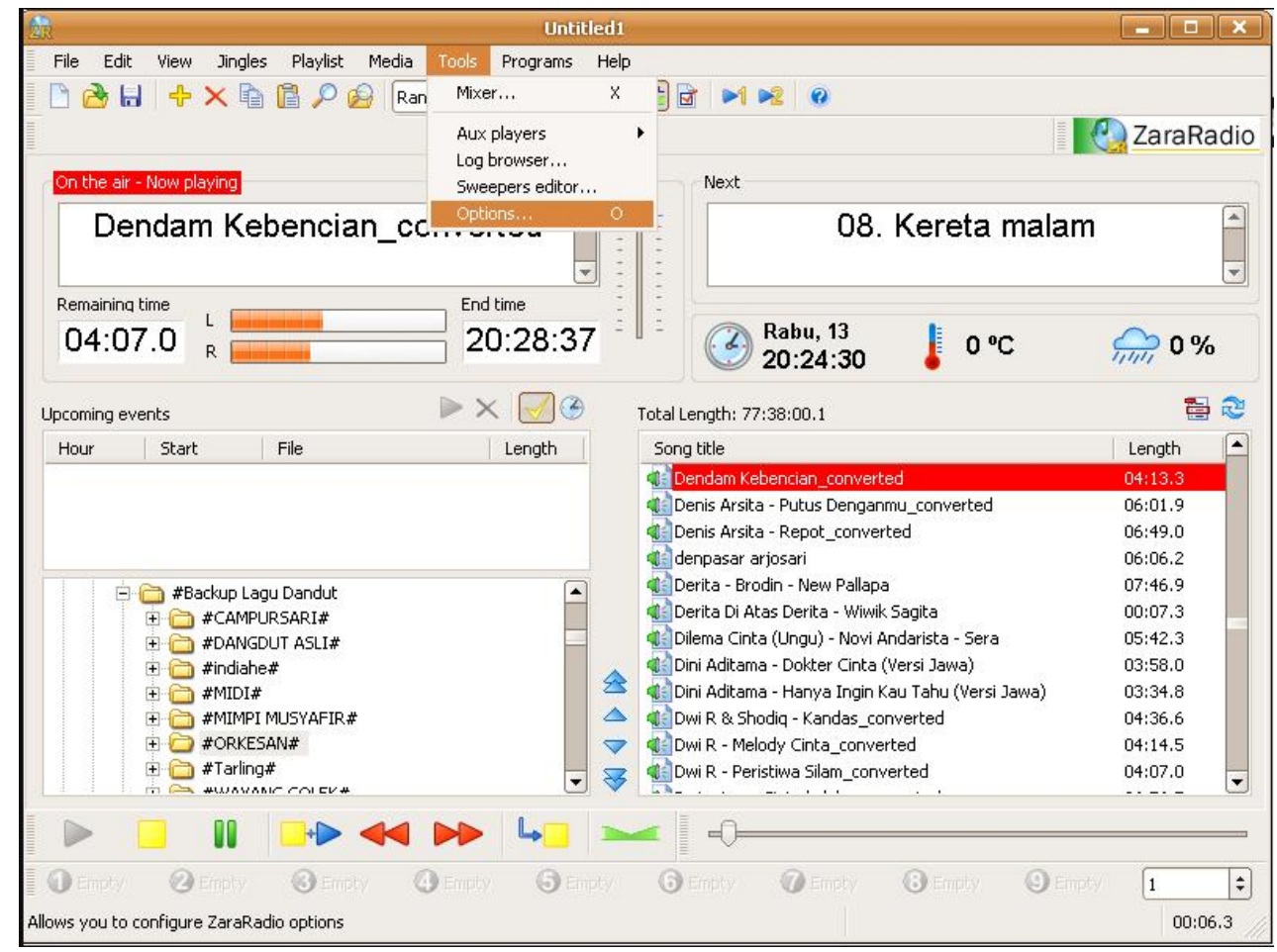

Gambar 13. Aplikasi Otomasi Siaran ZaraRadio

\section{KESIMPULAN}

Dalam penelitian ini, sistem siaran radio streaming yang terintegrasi telah berhasil diimplementasikan. Dari penelitian didapatkan kesimpulan sebagai berikut :

1. Raspberry Pi dapat digunakan untuk implementasi sebuah unit studio terintegrasi radio streaming. Bila diinginkan unit lain dalam jaringan studio terintegrasi, cukup dilakukan duplikasi pada mini PC Raspberry Pi dengan sedikit perubahan konfigurasi server masingmasing.

2. Radio streaming menggunakan Raspberry Pijuga berbiaya rendah dan efisien untuk digunakan pada stasiun radio yang bersifat portabel. Selain itu, penggunaan aplikasi server Icecast2-DarkIce sangat praktis karena tidak terlalu banyak membutuhkan pengetahuan teknis serta instalasi yang singkat.

3. Penggunaan WinAmp sebagai aplikasi otomasi siaran telah cukup memadai pada jaringan studio terintegrasi, sedangkan ZaraRadio memiliki keterbatasan pada penggunaan sumber audio streaming.

\section{REFERENSI}

[1] John Watkinson, 2002, An Introduction to Digital Audio., Focal Press. Boston-USA

[2] Andy Bailey, 2011. Network Technology for Digital Audio. Focal Press- Boston USA

[3]Aviom, 2012. A-Net v. Ethernet: Networking Designed for Audio. Aviom.com- Phoenix USA

[4] Audinate Corp, 2008. Recommended Network Topologies. Audinate- New South Wales Australia

[5] Michael Dosch, 2010. A network-enabled radio console architecture. Telos System Cleveland Ohio USA

[6] Matt Richardson, Shawn Wallace,2012 , "Getting Started with Raspberry", Brian Jepson, O'Reilly Media Inc., United States of America. 